Article

\title{
Predictive and Prognostic Significance of mRNA Expression and DNA Copies Aberrations of ERCC1, RRM1, TOP1, TOP2A, TUBB3, TYMS, and GSTP1 Genes in Patients with Breast Cancer
}

\author{
Matvey M. Tsyganov ${ }^{1,+}$, Marina K. Ibragimova ${ }^{1,2, *,+}$, Evgeniy Yu. Garbukov ${ }^{1}$, Irina A. Tsydenova ${ }^{1}(\mathbb{D}$, \\ Kseniya A. Gaptulbarova ${ }^{1}$, Daria S. Dolgasheva ${ }^{1}$, Ekaterina A. Zdereva ${ }^{1}$, Anastasia A. Frolova ${ }^{1}$, \\ Elena M. Slonimskaya ${ }^{1}$ and Nikolai V. Litviakov ${ }^{1}$ (D)
}

check for updates

Citation: Tsyganov, M.M.; Ibragimova, M.K.; Garbukov, E.Y.; Tsydenova, I.A.; Gaptulbarova, K.A.; Dolgasheva, D.S.; Zdereva, E.A.; Frolova, A.A.; Slonimskaya, E.M.; Litviakov, N.V. Predictive and Prognostic Significance of mRNA Expression and DNA Copies Aberrations of ERCC1, RRM1, TOP1, TOP2A, TUBB3, TYMS, and GSTP1 Genes in Patients with Breast Cancer. Diagnostics 2022, 12, 405. https:// doi.org/10.3390/diagnostics12020405 Academic Editor: Sung Chul Lim Received: 29 December 2021 Accepted: 3 February 2022 Published: 4 February 2022 Publisher's Note: MDPI stays neutral with regard to jurisdictional claims in published maps and institutional affiliations.

Copyright: (C) 2022 by the authors. Licensee MDPI, Basel, Switzerland. This article is an open access article distributed under the terms and conditions of the Creative Commons Attribution (CC BY) license (https:// creativecommons.org/licenses/by/ $4.0 /)$.
1 Cancer Research Institute, Tomsk National Research Medical Center of the Russian Academy of Sciences, 634050 Tomsk, Russia; tsyganovmm@yandex.ru (M.M.T.); jrmaximum@rambler.ru (E.Y.G.); tsydenova422@gmail.com (I.A.T.); xenia.gaptulbarova@yandex.ru (K.A.G.); normikus.18.97@gmail.com (D.S.D.); zdereva.e@gmail.com (E.A.Z.); anastasiya10152@gmail.com (A.A.F.); slonimskaya@rambler.ru (E.M.S.); nvlitv72@yandex.ru (N.V.L.)

2 National Research Tomsk State University, 634050 Tomsk, Russia

* Correspondence: imk1805@yandex.ru

+ These authors contributed equally to this work.

\begin{abstract}
Increasingly, many researchers are focusing on the sensitivity in breast tumors (BC) to certain chemotherapy drugs and have personalized their research based on the assessment of this sensitivity. One such personalized approach is to assess the chemotherapy's gene expression, as well as aberrations in the number of DNA copies-deletions and amplifications with the ability to have a significant effect on the gene's activity. Thus, the aim of this work was to study the predictive and prognostic significance of the expression and chromosomal aberrations of eight chemosensitivity genes in breast cancer patients. Material and methods. The study involved 97 patients with luminal B breast cancer IIB-IIIB stages. DNA and RNA were isolated from samples of tumor tissue before and after treatment. Microarray analysis was performed for all samples on high-density microarrays (DNA chips) of Affymetrix (USA) CytoScanTM HD Array and Clariom ${ }^{\mathrm{TM}} \mathrm{S}$ Assay, human. Detection of expression level of seven chemosensitivity genes-RRM1, ERCC1, TOP1, TOP2a, TUBB3, TYMS, and GSTP1-was performed using PCR real-time (RT-qPCR). Results. The expression of the RRM1 (AC scheme), TOP2 $\alpha, T Y M S$, and TUBB3 genes in patients with an objective response to treatment (complete and partial regression) is higher than in patients with stabilization and progression $(p<0.05)$. According to our results, the presence of a high level of GSTP1 in a tumor biopsy is associated with the low efficiency of the NAC CP scheme $(p=0.05)$. The presence of RRM1 deletion is associated with complete and partial regression, as for the TOP1 and TUBB3 genes $(p<0.05)$. Higher rates of metastatic survival are associated with a high level of expression and amplification of the GSTP1 gene (log-rank test $p=0.02$ and $p=0.05)$. Conclusion. Thus, a complex assessment of the chemotherapy's gene expression is important not only for understanding the heterogeneity and molecular biology of breast cancer but also to obtain a more accurate disease prognosis.
\end{abstract}

Keywords: chemotherapy's gene expression; copy number aberrations; neoadjuvant chemotherapy; efficiency; prognosis

\section{Introduction}

The most important aspect of personalized treatment of cancer patients is the resistance and sensitivity to specific chemotherapeutic drugs [1]. For this purpose, it is possible to determine markers of chemosensitivity in tumor tissue. Thus, many studies have shown that the expression and/or co-expression of several genes, such as ERCC1, RRM1, TOP1, $T O P 2 \alpha, T U B B 3, T Y M S$, and GSTP1, in tumor tissues is closely related to chemoresistance 
and prognosis in breast cancer patients (BC) [2]. It was found that the ERCC1 gene (excisional repair gene) is a structure-specific endonuclease involved in DNA repair. Clinical studies have shown that high ERCC1 expression is associated with resistance to platinumbased chemotherapy [3], as well as overexpression of glutathione-S-transferase P1 (GSTP1), which belongs to the family of metabolic enzymes, which is involved in the detoxification of some anticancer drugs by conjugating with glutathione [4], which is also associated with low efficacy of chemotherapy based on anthracyclines and taxanes, as well as low rates of disease-free and overall survival $[4,5]$.

Thymidylate synthase (TYMS) and ribonucleotide reductase (RRM1) are involved in the de novo formation of thymidylate and dNTP from ribonucleotides, respectively. The high expression of TYMS and low RRM1 significantly correlate with sensitivity to gemcitabine [6]. TUBB3 is a marker for docetaxel and paclitaxel resistance. The high expression levels correlate with low response in patients with taxanes chemotherapy [7]. The gene expression of the group of topoisomerase-topoisomerase 1 (TOP1) and $2 \alpha$ (TOP $2 \alpha$ ) - is important for doxorubicin. These enzymes change the topology of DNA and catalyze the unwinding of DNA supercoils and the breaking and stitching of nucleic acid molecules. The expression level of TOP $2 \alpha$ positively correlates with the efficacy of anthracycline drugs [8]. Several experimental and clinical studies confirm that both the expression of TOP $2 \alpha$ and the amplification are associated with a worse prognosis. At the same time, such patients are more sensitive to anthracyclines-based therapy, in particular doxorubicin and epirubicin [9].

It is important to note that studies of chromosomal aberrations, in particular, copy number aberrations (CNA) deletions and amplifications, are useful for studying the effect of the presented genes on the neoplasms chemosensitivity. It is well known that allelic deletion of a gene locus can significantly reduce its spontaneous expression and/or its ability to express in response to a stimulus, while amplification is the opposite [10]. It was found that with the deletion of the short arm of chromosome 18 (18p11.32), where the TYMS gene is localized, patients are immune to chemotherapy with 5-fluorouracil [6]. Amplification of 16q24.3 (localization of the TUBB3 gene) is associated with high efficiency of taxanes [11].

Thus, the assessment of the gene expression level before chemotherapy can be useful for choosing the correct and most effective treatment scheme. However, despite a large number of ongoing fundamental and clinical studies, there is no consensus regarding the predictive value of the studied criteria, or the selection of the scheme for breast cancer therapy.

In the present study, we analyzed the association of chemotherapy's genes expression in breast cancer tissue before and after neoadjuvant chemotherapy with the effect of therapy, as well as indicators of metastatic survival.

\section{Materials and Methods}

\section{Patients and Treatment}

The study involved 97 luminal $B$ breast cancer patients of stages IIA-IIIB $\left(\mathrm{T}_{1-4} \mathrm{~N}_{0-3} \mathrm{M}_{0}\right)$ with morphologically verified diagnosis, aged 24-68, with the average age being $46.97 \pm$ 1.08 years old (Mean $\pm \mathrm{SE}$ ), who received treatment in the clinics of the Research Institute of Oncology (Tomsk, Russia) in 2006-2020. The research was conducted in accordance with the 1964 Helsinki Declaration (amended in 2013) and the local ethics committee of the institute (protocol 1 dated 14 January 2013), and all patients signed an informed consent for the study. All patients with "Consensus conference on neoadjuvant chemotherapy in carcinoma of the breast, 26-28 April 2003, Philadelphia, Pennsylvania" [12] in the neoadjuvant regimen and received 4-8 courses of chemotherapy according to the schemes AC (adriamycin $50 \mathrm{mg} / \mathrm{m}^{2}$ and cyclophosphamide $600 \mathrm{mg} / \mathrm{m}^{2}$ once every 3 weeks), AT (adriamycin $50 \mathrm{mg} / \mathrm{m}^{2}$ and Taxotere $75 \mathrm{mg} / \mathrm{m}^{2}$ ), ACT (adriamycin $50 \mathrm{mg} / \mathrm{m}^{2}$, cyclophosphamide $600 \mathrm{mg} / \mathrm{m}^{2}$, and Taxotere $75 \mathrm{mg} / \mathrm{m}^{2}$ ), CAX (cyclophosphamide $100 \mathrm{mg} / \mathrm{m}^{2}$ intramuscularly, adriamycin $30 \mathrm{mg} / \mathrm{m}^{2}$ intravenously, and xeloda $1200 \mathrm{mg} / \mathrm{m}^{2}$ orally), or CP (cyclophosphamide 
$1080 \mathrm{mg} / \mathrm{m}^{2}$, cisplatin $\left.135 \mathrm{mg}\right)$, or monotherapy with Taxotere $\left(100 \mathrm{mg} / \mathrm{m}^{2}\right.$ hourly infusion per day). The operation was performed 3-5 weeks after NAC in the amount of radical or subcutaneous mastectomy, radical resection, sectoral resection with axillary lymphadenectomy, or another type of organ-preserving surgery; then, the patients underwent radiation and/or hormonal or targeted therapy (Herceptin in HER2+ status) according to indications. During the entire period, the patients were monitored dynamically. Median follow-up time was 40 months $(40.0 \pm 2.79)$. The main clinical and pathological characteristics are presented in Table 1.

Table 1. The main clinical and pathological parameters of patients.

\begin{tabular}{ccc}
\hline \multicolumn{2}{c}{ Clinical and Pathological Parameter } & The Number of Patients, abs.n. (\%) \\
\hline \multirow{2}{*}{ Age } & $\leq 45$ & $44(45.4)$ \\
Menstrual status & $>45$ & $53(54.6)$ \\
& Premenopause & $51(52.6)$ \\
Tumor size & Postmenopause & $46(47.4)$ \\
& $\mathrm{T}_{1}$ & $15(15.5)$ \\
& $\mathrm{T}_{2}$ & $71(73.2)$ \\
$\mathrm{T}_{3}$ & $5(5.2)$ \\
Lymphogenous metastasis & $\mathrm{T}_{4}$ & $6(6.2)$ \\
& $\mathrm{N}_{0}$ & $40(41.2)$ \\
Histological form & $\mathrm{N}_{1}$ & $44(45.4)$ \\
& $\mathrm{N}_{2}$ & $6(6.2)$ \\
Histological type & $\mathrm{N}_{3}$ & $7(7.2)$ \\
& Unicentric & $39(40.2)$ \\
& Multicentric & $58(59.8)$ \\
& Invasive ductal carcinoma & $54(55.7)$ \\
& Invasive lobular & $43(44.3)$ \\
& carcinoma & $19(19.6)$ \\
NAC regimen & CAX & $30(30.9)$ \\
& AC & $21(21.6)$ \\
& Taxotere in mono & $16(16.5)$ \\
NAC effect & AT/ACT & $11(11.3)$ \\
& CP & $11(11.3)$ \\
& Complete regression & $58(59.8)$ \\
& Partial regression & $25(25.8)$ \\
& Stabilization & $3(3.1)$ \\
\hline
\end{tabular}

We analyzed biopsy tumor samples before treatment ( 10 $\mathrm{mm}^{3}$ volume), obtained under the control of ultrasound and surgical samples after NAC $\left(\sim 60-70 \mathrm{~mm}^{3}\right.$ volume) $3-5$ weeks after the last course of neoadjuvant chemotherapy. Tumor samples were placed in an RNAlater solution (Sigma, St. Louis, MO, USA) and stored at $-80^{\circ} \mathrm{C}$ (after a $24-\mathrm{h}$ incubation at $+4{ }^{\circ} \mathrm{C}$ ) for further DNA isolation.

RNA extraction. Total RNA was isolated from paired samples using the RNeasy Mini kit Plus kit (Qiagen, Germany \#51304). The concentration and purity of RNA isolation was evaluated on a NanoDrop-2000 spectrophotometer (Thermo Fisher, Waltham, MA, USA). RNA concentration was 25-100 ng $/ \mu \mathrm{L}, \mathrm{A}_{260} / \mathrm{A}_{280}=1.75-1.90$, and $\mathrm{A}_{260} / \mathrm{A}_{230}=1.80$ 2.00. RNA integrity was assessed by capillary electrophoresis on a TapeStation instrument (Agilent Technologies, Santa Clara, CA, USA); DNA fragments had a mass of more than $60 \mathrm{kbp}$. RIN was 6.6-9.2. To obtain cDNA on an RNA template, a reverse transcription reaction was performed using a RevertAid ${ }^{\mathrm{TM}}$ kit (Thermo Fisher, Waltham, MA, USA) with random hexanucleotides.

Quantitative PCR. The expression level of genes RRM1, ERCC1, TOP1, TOP2a, TUBB3, TYMS, and GSTP1 was assessed using reverse transcriptase quantitative real-time PCR (RTqPCR) with original primers and probes using TaqMan technology on a Rotor-Gene-6000 amplifier (Corbett Research, Mortlake, NSW, Australia). PCR was set up in three replicas in a volume of $15 \mu \mathrm{L}$ containing $250 \mu \mathrm{M}$ dNTPs (Sibenzyme, Novosibirsk, Russia), $300 \mathrm{nM}$ 
forward and reverse primers, $200 \mathrm{nM}$ probe, $2.5 \mathrm{mM} \mathrm{MgCl}$, 19 SE buffer (67 mM Tris- $\mathrm{HCl}$ pH 8.8 at $25{ }^{\circ} \mathrm{C}, 16.6 \mathrm{mM}$ (NH4) 2SO4, and 0.01\% Tween-20), 2.5 units of HotStart Taq polymerase (Sibenzyme, Russia), and $50 \mathrm{ng}$ of cDNA. The two-step amplification program included 1 cycle-94 ${ }^{\circ} \mathrm{C}, 10 \mathrm{~min}$-pre-denaturation; and 40 cycles-1 step $94{ }^{\circ} \mathrm{C}, 10 \mathrm{~s}$, and 2 steps $20 \mathrm{~s}$ - at a temperature of $60{ }^{\circ} \mathrm{C}$. Two referee genes were used as the referee gene: GAPDH (glyceraldehydes-3-phosphatedehydrogenase) and ACTB (actin beta), and the level of gene expression was normalized in relation to the expression of the referee genes and measured in arbitrary units. Relative expression was estimated using the Pfaffl method [13]. If the level of gene expression was more than 1 (higher than in normal tissue), then high expression was stated; if the level of gene expression was less than 1 (lower than in normal tissue), then low expression was stated. Primers and probes are presented in Table 2.

Table 2. Sequence of primers and probes.

\begin{tabular}{|c|c|c|}
\hline Gene & Amplicon (bp) & Sequence \\
\hline GAPDH & $124 \mathrm{bp}$ & $\begin{array}{c}\text { F } 5^{\prime} \text {-gccagccgagccacatc- } 3^{\prime} \\
\text { R 5 }{ }^{\prime} \text {-ggcaacaatatccactttaccaga- } 3^{\prime} \\
\text { Probe } 5^{\prime} \text {-cgcccaatacgaccaaatccg- } 3^{\prime}\end{array}$ \\
\hline RRM1 & $94 \mathrm{bp}$ & $\begin{array}{c}\text { F } 5^{\prime} \text {-actaagcaccctgactatgctatcc-3' } \\
\text { R } 5^{\prime} \text {-cttccatcacatcactgaacacttt- } 3^{\prime} \\
\text { Probe } 5^{\prime} \text {-cagccaggatcgctgtctctaacttgca-3' } \\
\text { F } 5^{\prime} \text {-ggcgacgtaattccgacta- } 3^{\prime}\end{array}$ \\
\hline ERCC1 & $121 \mathrm{bp}$ & $\begin{array}{c}\text { R } 5^{\prime} \text {-agttcttcccaggctctgc- } 3^{\prime} \\
\text { Probe } 5^{\prime} \text {-accacaacctgcacccagactacatcca- } 3^{\prime} \\
\text { F } 5^{\prime} \text {-ggcgagtgaatctaaggataatgaa }-3^{\prime}\end{array}$ \\
\hline TOP1 & $97 \mathrm{bp}$ & $\begin{array}{c}\text { R } 5^{\prime} \text { - tggatatcttaaagggtacagcgaa }-3^{\prime} \\
\text { Probe } 5^{\prime} \text {-accattttcccatcatcctttgttctgagc }-3^{\prime} \\
\text { F } 5^{\prime} \text {-agtcgctttcagggttcttgag- } 3^{\prime}\end{array}$ \\
\hline TOP $2 \alpha$ & $75 \mathrm{bp}$ & $\begin{array}{c}\text { R } 5^{\prime} \text {-tttcatttacaggctgcaatgg- } 3^{\prime} \\
\text { Probe } 5^{\prime} \text {-cccttcacgaccgtcaccatgga- } 3^{\prime} \\
\text { F } 5^{\prime} \text {-gggccaagttctgggaagtc- } 3^{\prime}\end{array}$ \\
\hline ТUВВ3 & $71 \mathrm{bp}$ & $\begin{array}{c}\mathrm{R} 5^{\prime} \text {-cgagtcgccacgtagttg- } 3^{\prime} \\
\text { Probe } 5^{\prime} \text {-atgagcatggcatcgacccagc- } 3^{\prime} \\
\text { F } 5^{\prime} \text {-tctggaagggtgttttgga- } 3^{\prime}\end{array}$ \\
\hline TYMS & $91 \mathrm{bp}$ & $\begin{array}{c}\mathrm{R} 5^{\prime} \text {-tcccagattttcactccctt- } 3^{\prime} \\
\text { Probe } 5^{\prime} \text {-tctttagcatttgtggatcccttga- } 3^{\prime}\end{array}$ \\
\hline GSTP1 & $84 \mathrm{bp}$ & $\begin{array}{c}\text { F } 5^{\prime} \text {-ctggtggacatggtgaatgac- } 3^{\prime} \\
\text { R } 5^{\prime} \text {-cttgcccgcctcatagttg- } 3^{\prime} \\
\text { Probe } 5^{\prime} \text {-aggacctccgctgcaaatacatctc- } 3^{\prime}\end{array}$ \\
\hline
\end{tabular}

Note: all probes-FAM $\rightarrow$ BHQ1; NM-RNA sequence number in NCBI nucleotide database (http://www.ncbi. nlm.nih.gov/nuccore, accessed on 2 February 2022); bp—base pair; F-forward primer; R-reversed praimer; Probe-probe.

DNA extraction. DNA was isolated from 97 samples of tumor tissue using the QIAamp DNA mini Kit (Qiagen, Germany). DNA concentration and purity of isolation were evaluated on a Qubit 4.0 (Thermo Fisher Scientific, USA) from 50 to $250 \mathrm{ng} / \mu \mathrm{L}$. DNA integrity was assessed by capillary electrophoresis on a TapeStation instrument (Agilent Technologies, USA), and DNA fragments had a mass of more than $60 \mathrm{kbp}$.

Microarray analysis. Microarray analysis was performed on high-density microarrays (DNA chips) of Affymetrix (USA) CytoScanTM HD Array, which contain 1 million 900 thousand markers non-polymorphic markers for the analysis of copy number aberrations (CNA). Sample preparation, hybridization, and scanning procedures were performed in accordance with the protocol on the Affymetrix GeneChip ${ }^{\circledR}$ Scanner $30007 \mathrm{G}$ system (Affymetrix, Santa Clara, CA, USA). The Chromosome Analysis Suite 4.3 software (Affymetrix, USA) was used to process the microchipping results, which was specially developed for analyzing the results of microchipping on the CytoScanTM HD Array. 
Statistical data processing. Statistical data processing was carried out using the software package Statistica 8.0 (StatSoft Inc., Palo Alto, CA, USA). The Shapiro-Wilk Criterion was used to check the normality of the sample. For each sample, medians and an interquartile range of $25-75 \%$ were calculated. To test the hypothesis about the significance of differences between the study groups, the nonparametric Wilcoxon-Mann-Whitney test was used. For the analysis of metastatic-free survival (MFS), the survival curves constructed by the Kaplan-Meier method and the log-rank test were used. The Chi-square test was used to assess differences in frequencies (http:/ / vassarstats.net/index.html, accessed on 2 February 2022). ROC analysis and multivariate Cox analysis were performed using the IBM SPSS Statistics software. As a quantitative interpretation of the ROC analysis, the AUC (Area Under Curve) indicator is given.

\section{Results}

At the first stage of the study, we assessed the relationship between the expression and aberrations of the DNA copy number of the genes of chemosensitivity with the main clinical and pathological parameters (Tables S1 and S2). Significant differences are shown for the TOP1 gene in the expression level. The postoperative level of this gene is higher in patients with a large primary tumor node $(1.34 \pm 0.57)$, compared with patients in the $\mathrm{T}_{1-2}$ group $(0.85 \pm 0.28)$, with $p=0.02$. The menstrual status is important for the TOP $2 \alpha$ gene. In patients with preserved menstrual function, there is a more increased expression of topoisomerase $2 \alpha(8.84 \pm 2.23)$ than in postmenopausal patients $(4.16 \pm 1.44), p=0.05$. Only the histological tumor form is associated with the frequency of chromosomal aberrations in genes (Table S2). It was found that the frequency of deletions, in the case of the ERCC1 gene, is higher in the unicentric form $(17.9 \%, 7 / 39$ cases) than in the multicentric form $(3.4 \%$, $2 / 58$ cases), $p=0.03$. The opposite picture is observed for the TYMS gene: deletions were found in 14 out of 58 patients $(24.1 \%)$ in the multicentric form and in 6 out of 39 patients $(15.4 \%)$ in the unicentric form. The differences are statistically significant, $p=0.03$.

Then, we analyzed the relationship between the expression of the studied genes and the effect of neoadjuvant chemotherapy (Figure 1).

Statistically significant differences in the level of expression were found for the RRM1 gene in patients treated with the AC regimen (Figure 1B). The expression of this gene is higher (median: 0.61; percentile 25-75\%: 0.44-1.02) in patients with an objective response to treatment (complete and partial regression), compared with patients with stabilization and progression (median: 0.31 ; percentile 25-75\%: 0.16-0.41), with $p=0.04$. With the same treatment regimen, it was found that high levels of topoisomerase $2 \alpha$ (TOP $2 \alpha$ ) expression, as well as the thymidylate synthase gene (TYMS), are associated with an objective response to treatment, $p=0.03$ for both genes (Figure 1B).

A similar result was shown for the TUBB3 gene in patients treated with taxotere in mono-regimen (Figure 1B). The expression level was 2.5 times higher in patients with complete and partial regression (median: 1.71; percentile $25-75 \%$ : $0.32-4.16$ versus median: 0.97 ; and percentile $25-75 \%: 0.89-1.11, p=0.03$ ). An interesting result was shown in analyzing the expression of glutathione S-transferase P1, which is involved in the metabolism of platinum drugs, in particular carboplatin and cisplatin. P1 expression is directly related to the clinical response to chemotherapy treatment [14]. According to our results, the high level of GSTP1 in a tumor biopsy is associated with low efficiency of CP NAC scheme, compared with the group of patients with a low level of expression and objective response to treatment (median: 0.29; percentile 25-75\%: 0.07-0.51 versus median: 0.04; percentile 25-75\%: 0.00-1.12, $p=0.05$ ), (Figure 1F). In other cases, the level of expression of the studied genes was not associated with the effect of neoadjuvant chemotherapy. 

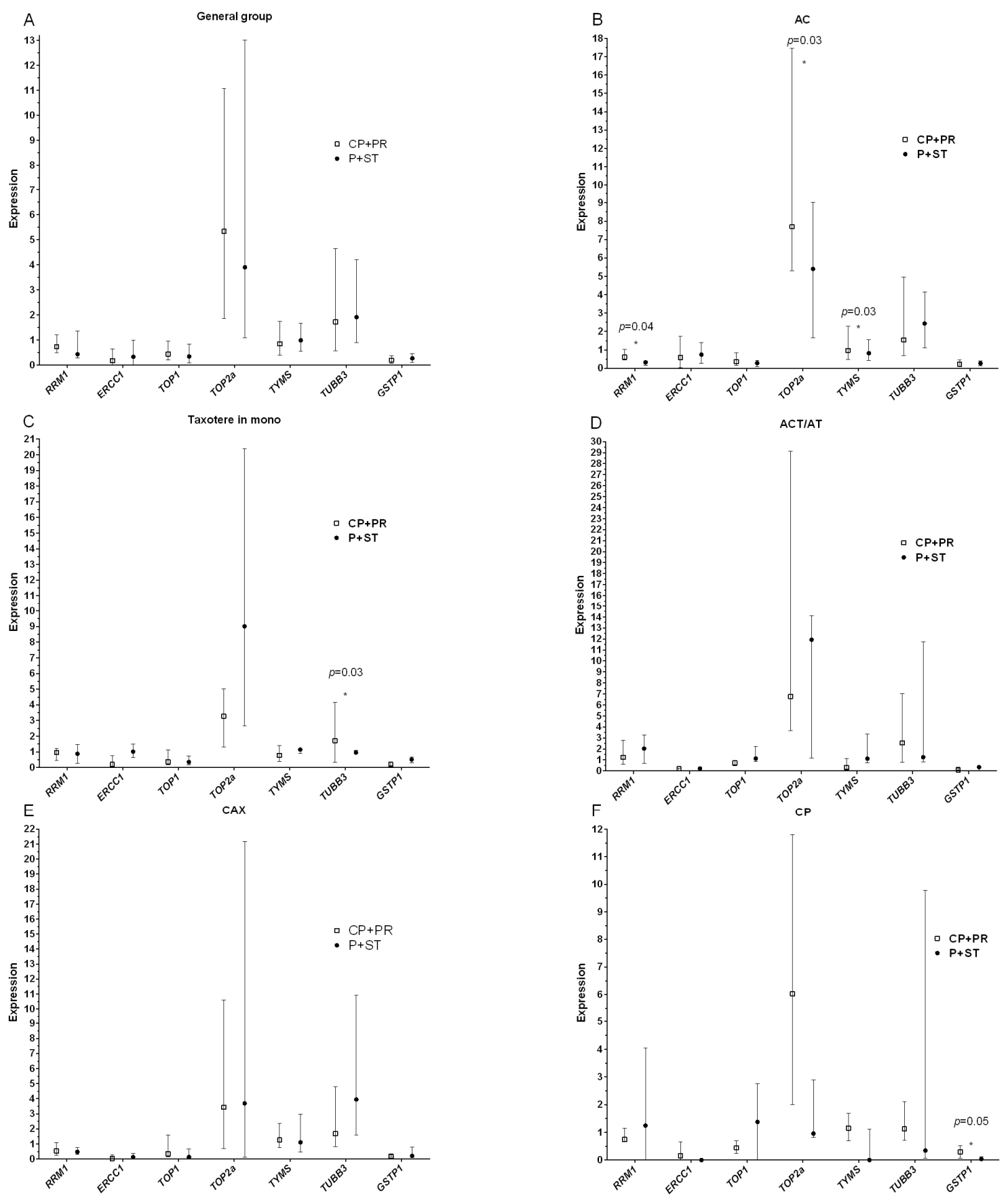

Figure 1. Diagrams of the relationship between the initial level of mRNA expression and the NAC effect in the general group of patients (A), depending on the chemotherapy scheme: (B) - scheme AC, (C)—scheme Taxotere in mono-regimen, (D)—scheme AT/ACT, (E)—scheme CAX, (F)—scheme CP. Note: $\mathrm{CR}+\mathrm{PR}$ - complete and partial regression; P + ST-progression and stabilization; * statistically significant result. The figure shows the medians of expression and the interquartile range of $25-75 \%$ for each gene in patient groups depending on the effect of NAC.

Further analysis of the relationship of chromosomal aberrations in the studied genes in patients with breast cancer showed that CNA weakly correlates with the NAC effect (Table 3). 
Table 3. Frequency of chromosomal aberrations in genes chemosensitivity depending on the effect and NAC.

\begin{tabular}{|c|c|c|c|c|c|c|c|c|c|c|c|c|c|}
\hline \multirow{2}{*}{ Genes } & \multirow{2}{*}{ CNA } & \multicolumn{2}{|c|}{ General Group } & \multicolumn{2}{|c|}{ CAX } & \multicolumn{2}{|c|}{ AC } & \multicolumn{2}{|c|}{ Taxotere in Mono } & \multicolumn{2}{|c|}{ ACT/AT } & \multicolumn{2}{|c|}{$\mathrm{CP}$} \\
\hline & & $\mathbf{C R}+\mathbf{P R}$ & $\mathbf{P}+\mathrm{ST}$ & $\mathrm{CR}+\mathrm{PR}$ & $P+S T$ & $\mathrm{CR}+\mathrm{PR}$ & $\mathbf{P}+\mathrm{ST}$ & $\mathrm{CR}+\mathrm{PR}$ & $P+S T$ & $\mathrm{CR}+\mathrm{PR}$ & $P+S T$ & $\mathrm{CR}+\mathrm{PR}$ & $P+S T$ \\
\hline \multirow{4}{*}{ RRM1 } & Loss & $24(34.8)$ & $3(10.7)$ & $6(50.0)$ & $0(0.0)$ & $9(45.0)$ & $1(10.0)$ & $3(18.8)$ & $1(20.0)$ & $4(30.8)$ & $0(0.0)$ & $2(25.0)$ & $1(33.3)$ \\
\hline & $\mathrm{n}$ & $42(60.9)$ & $22(78.6)$ & $6(50.0)$ & $6(85.7)$ & $10(50.0)$ & $8(80.0)$ & $13(81.3)$ & $4(80.0)$ & $8(61.5)$ & $2(66.7)$ & $5(62.5)$ & $2(66.7)$ \\
\hline & Gain & $3(4.3)$ & $3(10.7)$ & $0(0.0)$ & $1(14.3)$ & $1(5.0)$ & $1(10.0)$ & $0(0.0)$ & $0(0.0)$ & $1(7.7)$ & $1(33.3)$ & $1(12.5)$ & $0(0.0)$ \\
\hline & $p$-level & \multicolumn{2}{|c|}{0.04} & \multicolumn{2}{|c|}{0.04} & \multicolumn{2}{|c|}{0.15} & \multicolumn{2}{|c|}{1} & \multicolumn{2}{|c|}{0.32} & \multicolumn{2}{|c|}{0.80} \\
\hline \multirow{3}{*}{ ERCC1 } & Loss & $6(8.7)$ & $4(14.3)$ & $3(25.0)$ & $1(14.3)$ & $1(5.0)$ & $1(10.0)$ & $1(6.3)$ & $0(0.0)$ & $0(0.0)$ & $0(0.0$ & $1(12.5)$ & $2(66.7)$ \\
\hline & Gain & $3(4.3)$ & $1(3.6)$ & $0(0.0)$ & $0(0.0)$ & $1(5.0)$ & $0(0.0)$ & $0(0.0)$ & $1(20.0)$ & $2(15.4)$ & $0(0.0)$ & $0(0.0)$ & $0(0.0)$ \\
\hline & $p$-level & \multicolumn{2}{|c|}{0.70} & \multicolumn{2}{|c|}{0.85} & \multicolumn{2}{|c|}{0.68} & \multicolumn{2}{|c|}{0.16} & \multicolumn{2}{|c|}{1} & \multicolumn{2}{|c|}{0.15} \\
\hline \multirow{4}{*}{ TOP1 } & Loss & $3(4.3)$ & $0(0.0)$ & $3(25.0)$ & $0(0.0)$ & $0(0.0)$ & $0(0.0)$ & $0(0.0)$ & $0(0.0)$ & $0(0.0)$ & $0(0.0)$ & $0(0.0)$ & $0(0.0)$ \\
\hline & $\mathrm{n}$ & $42(60.9)$ & $23(82.1)$ & $3(25.0)$ & $6(85.7)$ & $10(50.0)$ & $8(80.0)$ & $14(87.5)$ & $5(100.0)$ & $8(61.5)$ & $2(66.7)$ & 7 (87.5) & $2(66.7)$ \\
\hline & Gain & $24(34.8)$ & 5 (17.9) & $6(50.0)$ & $1(14.3)$ & $10(50.0)$ & $2(20.0)$ & $2(12.5)$ & $0(0.0)$ & $5(38.5)$ & $1(33.3)$ & 1 (12.5) & 1 (33.3) \\
\hline & $p$-level & \multicolumn{2}{|c|}{0.10} & \multicolumn{2}{|c|}{0.03} & \multicolumn{2}{|c|}{0.28} & \multicolumn{2}{|c|}{1} & \multicolumn{2}{|c|}{1} & \multicolumn{2}{|c|}{0.99} \\
\hline ТОР2a & $\mathrm{n}$ & $38(55.1)$ & 15 (53.6) & $4(33.3)$ & $5(71.4)$ & $11(55.0)$ & $4(40.0)$ & $11(68.8)$ & $3(60.0)$ & $9(69.2)$ & $2(66.7)$ & $3(37.5)$ & 1 (33.3) \\
\hline & Gain & $17(24.6)$ & $5(17.9)$ & $5(41.7)$ & $1(14.3)$ & $6(30.0)$ & $3(30.0)$ & $2(12.5)$ & $0(0.0)$ & $4(30.8)$ & $1(33.3)$ & $0(0.0)$ & $0(0.0)$ \\
\hline & $p$-level & & & & & & & & & & & & \\
\hline & Loss & $21(30.4)$ & 4 (14.3) & $6(50.0)$ & $0(0.0)$ & $7(35.0)$ & $2(20.0)$ & $4(25.0)$ & $0(0.0)$ & $3(23.1)$ & $0(0.0)$ & 1 (12.5) & $2(66.7)$ \\
\hline TYMS & $\mathrm{n}$ & 45 (65.2) & $21(75.0)$ & 5 (41.7) & $6(85.7)$ & $13(65.0)$ & 7 (70.0) & $12(75.0)$ & $4(80.0)$ & $8(61.5)$ & $3(100.0)$ & 7 (87.5) & 1 (33.3) \\
\hline & Gain & $3(4.3)$ & 3 (10.7) & $1(8.3)$ & $1(14.3)$ & $0(0.0)$ & $1(10.0)$ & $0(0.0)$ & $1(20.0)$ & $2(15.4)$ & $0(0.0)$ & $0(0.0)$ & $0(0.0)$ \\
\hline & $p$-level & & & & & & & & & & & & \\
\hline & Loss & $41(59.4)$ & $4(22.2)$ & 5 (41.7) & $3(42.9)$ & $10(50.0)$ & $6(60.0)$ & 13 (81.3) & $4(80.0)$ & $10(76.9)$ & $1(33.3)$ & $3(37.5)$ & $0(0.0)$ \\
\hline ТUВВ3 & $\mathrm{n}$ & $25(36.2)$ & $13(72.2)$ & $5(41.7)$ & 4 (57.1) & $10(50.0)$ & $4(40.0)$ & 3 (18.8) & $1(20.0)$ & $1(7.7)$ & $1(33.3)$ & $4(50.0)$ & $3(100.0)$ \\
\hline & Gain & $3(4.3)$ & $1(5.6)$ & $2(16.7)$ & $0(0.0)$ & $0(0.0)$ & $0(0.0)$ & $0(0.0)$ & $0(0.0)$ & $2(15.4)$ & $1(33.4)$ & $1(12.5)$ & $0(0.0)$ \\
\hline & $p$-level & & & & & & & & & & & & \\
\hline
\end{tabular}


Table 3. Cont.

\begin{tabular}{|c|c|c|c|c|c|c|c|c|c|c|c|c|c|}
\hline \multirow{2}{*}{ Genes } & \multirow{2}{*}{ CNA } & \multicolumn{2}{|c|}{ General Group } & \multicolumn{2}{|c|}{ CAX } & \multicolumn{2}{|c|}{ AC } & \multicolumn{2}{|c|}{ Taxotere in Mono } & \multicolumn{2}{|c|}{ ACT/AT } & \multicolumn{2}{|c|}{$\mathrm{CP}$} \\
\hline & & $\mathrm{CR}+\mathrm{PR}$ & $P+S T$ & $\mathrm{CR}+\mathrm{PR}$ & $P+S T$ & $\mathrm{CR}+\mathrm{PR}$ & $P+S T$ & $\mathrm{CR}+\mathrm{PR}$ & $P+S T$ & $\mathrm{CR}+\mathrm{PR}$ & $P+S T$ & $\mathrm{CR}+\mathrm{PR}$ & $P+S T$ \\
\hline \multirow{3}{*}{ GSTP1 } & Loss & $7(10.1)$ & $4(14.3)$ & $3(25.0)$ & $2(28.6)$ & $2(10.0)$ & $1(10.0)$ & $0(0.0)$ & $1(20.0)$ & $2(15.4)$ & $0(0.0)$ & $0(0.0)$ & $0(0.0)$ \\
\hline & Gain & $16(23.2)$ & $4(14.3)$ & $4(33.3)$ & $0(0.0)$ & $3(15.0)$ & $2(20.0)$ & $4(25.0)$ & $0(0.0)$ & $4(30.8)$ & $1(33.3)$ & $1(12.5)$ & $1(33.3)$ \\
\hline & $p$-level & \multicolumn{2}{|c|}{0.56} & \multicolumn{2}{|c|}{0.21} & \multicolumn{2}{|c|}{0.94} & \multicolumn{2}{|c|}{0.10} & \multicolumn{2}{|c|}{0.76} & \multicolumn{2}{|c|}{0.99} \\
\hline
\end{tabular}

Note: $\mathrm{CR}+\mathrm{PR}$-complete and partial regression; P+ST—progression and stabilization. Statistically significant differences are in bold. 
It was found that the presence of $R R M 1$ deletion in $37.8 \%$ of cases determines an objective response to treatment, while in patients with stabilization and progression, the deletion of this gene is observed only in $10.7 \%$ of cases $(p=0.04)$. A similar result was established with the CAX chemotherapy. An interesting result was obtained for the TOP1 gene. The normal copy number of topoisomerase 1 in patients treated with the CAX scheme was associated with a lack of response to treatment in $85.7 \%$ of patients $(6 / 7$ cases, $p=0.03) ; 50 \%$ of patients with a thymidylate synthase deletion responded to the CAX treatment, while in patients with stabilization and progression, no deletions were observed (the relationship was at the level of a pronounced trend, $p=0.07$ ) (Table 3).

The presence of TUBB3 deletion is decisive for the presence of an objective response For the TUBB3 gene. The frequency of deletions is statistically significantly higher (41/69, $59.4 \%$ ) in patients with complete and partial regression than in the other group. At the same time, it is important to note that CNA does not affect the effectiveness of treatment in the group of patients treated with taxotere in mono-regimen.

Analysis of metastatic-free survival rates depending on expression, as well as CNA of the studied genes, is presented in Figures 2 and 3. If the level of gene expression was more than 1 (higher than in normal tissue), then high expression was stated; if the level of gene expression was less than 1 (lower than in normal tissue), then low expression was stated. As a result, it was found that statistically significant differences are observed only for the GSTP1 gene (Figure 2).

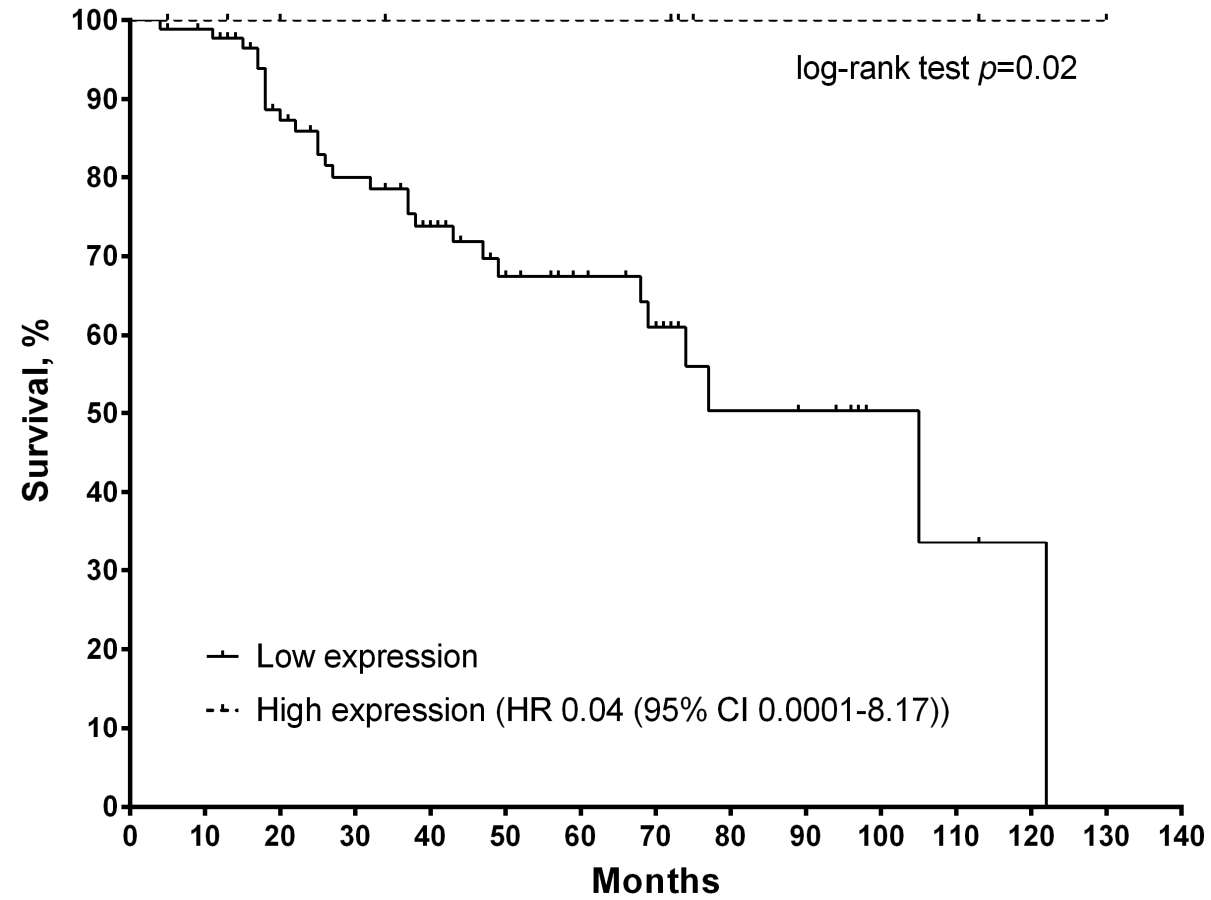

Figure 2. Curves of metastatic survival of breast cancer patients depending on the level of mRNA expression in the surgical material of the GSTP1 gene (log-rank test $p=0.02$ ). 

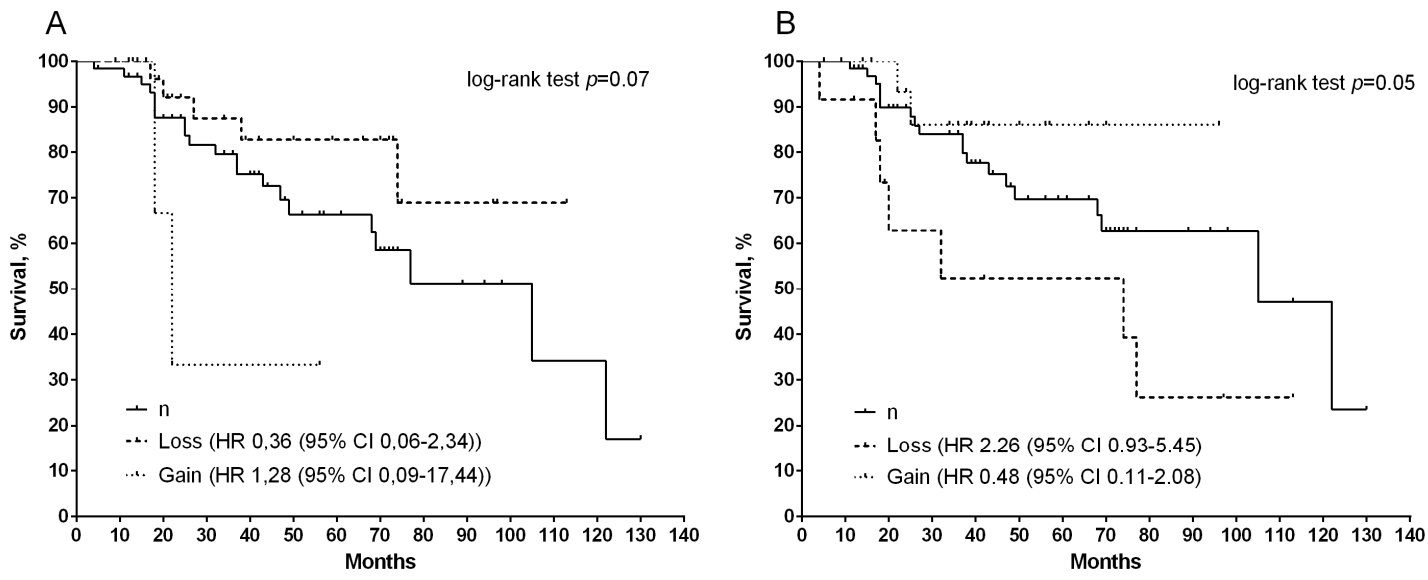

Figure 3. Curves of metastatic survival of patients with breast cancer, depending on CNA gene RRM1 (A) and GSTP1 (B), (log-rank test $p=0.07$ and $p=0.05)$.

In the general group of patients with a GSTP1 level of more than 1, the 5-year survival rates were $100 \%$ versus $68 \%$ in the group with low expression (HR 0.04 (95\% CI 0.0001-8.17); $\log$-rank test $p=0.02$ ).

The study of the expression of other chemosensitivity genes showed an absent relationship, with metastatic survival rates either in the general group of patients or depending on the treatment scheme.

In addition, we also assessed the effect of chromosomal aberrations on metastatic free survival indicators (Figure 3). It was shown that patients with a deletion of the RRM1 gene have better survival rates than the normal copy number of this gene and amplification at the level of a pronounced trend (Figure 3A), whereas statistically significant differences (logrank test $p=0.05$ ) were shown for GSTP1. At the same time, the presence of amplification determines the high survival rate of patients (5-year MFS is $86 \%$ ), while with a deletion, this indicator slightly exceeds 50\% (Figure 3B).

The ROC analysis showed that only the gene GSTP1 (AUC $=0.677, p=0.01$ ) was significant. None of the remaining genes were significant: $R R M 1$ (AUC $=0.537, p=0.65$ ); ERCC1 $(\mathrm{AUC}=0.496, p=0.95)$; TOP1 (AUC =0.547, $p=0,53)$; TOP2a (AUC = 0.616, $p=0,12) ;$ TUBB3 (AUC $=0.604, p=0.16)$; and TYMS $(\mathrm{AUC}=0.613, p=0.12)$.

In addition, a multivariate regression analysis was performed to identify prognostic factors for metastasis-free survival (Table 4).

It was found that the presence of a deletion in the TYMS gene and amplification in GSTP1 are factors that increase the risk of tumor metastasis (HR $=0.17$; 95\% CI: 0.02-1.03, $p=0.05$ and $\mathrm{HR}=0.48 ; 95 \% \mathrm{CI}: 0.11-2.08, p=0.04$, respectively), whereas TUBB3 deletion, on the contrary, caused a low risk of metastasis (HR $=5.31 ; 95 \% \mathrm{CI}: 0.99-28.36, p=0.05)$, as well as a high level of TOP $2 \alpha$ gene expression (HR $=3.29 ; 95 \%$ CI: 1.15-9.41, $p=0.02)$, (Table 4). Clinical and pathological parameters do not affect the risk of metastases. 
Table 4. Multivariate Cox regression analysis for metastasis-free survival of patients with breast cancer.

\begin{tabular}{|c|c|c|}
\hline \multirow{2}{*}{ Factor } & \multicolumn{2}{|c|}{ MFS } \\
\hline & HR $(95 \%$ CI $)$ & $p$-Value \\
\hline \multicolumn{3}{|c|}{ Clinical and pathological parameter } \\
\hline$\leq 45$ & 1.00 & \\
\hline$>45$ & $2.23(0.46-10.84)$ & 0.32 \\
\hline \multicolumn{3}{|l|}{ Tumor size } \\
\hline $\mathrm{T}_{1-2}$ & 1.00 & \\
\hline \multicolumn{3}{|l|}{ Lymphogenous metastasis } \\
\hline $\mathrm{N}_{0}$ & 1.00 & \\
\hline $\mathrm{N}_{1}$ & $0.93(0.22-3.95)$ & 0.92 \\
\hline $\mathrm{N}_{2}$ & $7.20(0.91-56.74)$ & 0.06 \\
\hline $\mathrm{N}_{3}$ & $6.57(0.90-48.16)$ & 0.06 \\
\hline \multicolumn{3}{|l|}{ Menstrual status } \\
\hline Premenopause & 1.00 & \\
\hline \multicolumn{3}{|l|}{ Histological type } \\
\hline Invasive ductal carcinoma & 1.00 & \\
\hline \multicolumn{3}{|l|}{ Histological form } \\
\hline Unicentric & 1.00 & \\
\hline \multicolumn{3}{|l|}{ NAC effect } \\
\hline Complete/Partial regression & 1.00 & \\
\hline Stabilization/Progression & $2.16(0.61-7.69)$ & 0.23 \\
\hline \multicolumn{3}{|c|}{ Copy number aberrations } \\
\hline \multicolumn{3}{|l|}{ RRM1 } \\
\hline $\mathrm{n}$ & 1.00 & \\
\hline Loss & $0.36(0.06-2.34)$ & 0.29 \\
\hline \multicolumn{3}{|l|}{ ERCC1 } \\
\hline $\mathrm{n}$ & 1.00 & \\
\hline Loss & $2.23(0.26-18.96)$ & 0.46 \\
\hline Gain & $0.98(0.06-16.34)$ & 0.99 \\
\hline \multicolumn{3}{|l|}{ TOP1 } \\
\hline $\mathrm{n}$ & 1.00 & \\
\hline Loss & $0.40(0.004-40.54)$ & 0.77 \\
\hline Gain & $1.46(0.10-20.69)$ & 0.38 \\
\hline \multicolumn{3}{|l|}{ TOP $2 \alpha$} \\
\hline $\mathrm{n}$ & 1.00 & \\
\hline Loss & $3.29(0.59-18.52)$ & 0.18 \\
\hline Gain & $0.39(0.05-2.81)$ & 0.35 \\
\hline \multicolumn{3}{|l|}{ TYMS } \\
\hline $\mathrm{n}$ & 1.00 & \\
\hline Loss & $0.17(0.02-1.03)$ & 0.05 \\
\hline Gain & $1.36(0.09-18.92)$ & 0.82 \\
\hline \multicolumn{3}{|l|}{ TUBB3 } \\
\hline $\mathrm{n}$ & 1.00 & \\
\hline Loss & $5.31(0.99-28.36)$ & 0.05 \\
\hline Gain & $0.73(0.03-17.72)$ & 0.84 \\
\hline \multicolumn{3}{|l|}{ GSTP1 } \\
\hline $\mathrm{n}$ & 1.00 & \\
\hline Loss & $2.26(0.93-5.45)$ & 0.69 \\
\hline Gain & $0.48(0.11-2.08)$ & 0.04 \\
\hline
\end{tabular}


Table 4. Cont.

\begin{tabular}{|c|c|c|}
\hline & \multicolumn{2}{|c|}{ MFS } \\
\hline & HR (95\% CI) & $p$-Value \\
\hline \multicolumn{3}{|c|}{ Expression } \\
\hline$R R M 1$ & & \\
\hline Low expression & 1.00 & \\
\hline $\begin{array}{l}\text { High expression } \\
\text { ERCC1 }\end{array}$ & $1.18(0.15-9.44)$ & 0.88 \\
\hline Low expression & 1.00 & \\
\hline $\begin{array}{l}\text { High expression } \\
\text { TOP1 }\end{array}$ & $0.76(0.17-3.44)$ & 0.72 \\
\hline Low expression & 1.00 & \\
\hline $\begin{array}{l}\text { High expression } \\
\text { TOP } 2 \alpha\end{array}$ & $5.09(0.46-55.83)$ & 0.18 \\
\hline Low expression & 1.00 & \\
\hline $\begin{array}{l}\text { High expression } \\
\text { TYMS }\end{array}$ & 3.29 (1.15-9.41) & 0.02 \\
\hline Low expression & 1.00 & \\
\hline $\begin{array}{l}\text { High expression } \\
\text { TUBB3 }\end{array}$ & $1.21(0.21-6.89)$ & 0.83 \\
\hline Low expression & 1.00 & \\
\hline $\begin{array}{l}\text { High expression } \\
\text { GSTP1 }\end{array}$ & $0.37(0.08-1.76)$ & 0.21 \\
\hline Low expression & 1.00 & \\
\hline High expression & $0.09(0.003-2.86)$ & 0.17 \\
\hline
\end{tabular}

Note: Statistically significant differences are in bold.

\section{Discussion}

To date, it has been established that the expression and/or co-expression of genes for chemosensitivity in tumor tissues is closely related to chemoresistance and prognosis in patients with breast cancer [2]. According to these works, gene expression, although it showed a high relationship with the effectiveness of treatment, is a variable value. Therefore, it is necessary to assess additional parameters of the studied genes of chemosensitivity. In our study, in addition to assessing the expression of genes for chemosensitivity, we analyzed the aberrations of the DNA copy number. It was found that the presence of TUBB3 and RRM1 deletion in tumor biopsy material is associated with more effective treatment. Besides this, the presence of a deletion of GSTP1 and RRM1 determines higher MFS values. Our data are consistent with the literature data.

Ribonucleotide reductase consists of two subunits, $R R M 1$ and $R R M 2$, and is an enzyme that limits the rate of DNA synthesis [15]. The RRM1 gene is the main target for gemcitabine. It has been shown that high expression of RRM1 is associated with resistance to this chemotherapy drug in a lung tumor [16]. At the same time, we showed in our study that increased RRM1 expression in patients treated with the AC scheme and deletion in patients treated with the CAX scheme determines the presence of objective response to treatment. In another study, the authors showed that $R R M 1$ copy number aberrations (deletions and amplifications) were observed in $15.9 \%$ and $13.6 \%$ of patients, respectively. Their presence was associated with a decrease in survival rates (HR = 1.72, 95\% $\mathrm{CI}=1.05-2.79, p=0.03$ ) [17]. The high TYMS expression and low RRM1 significantly correlate with sensitivity to gemcitabine [6]. However, in other clinical studies of breast cancer [18], lung cancer [19], and colorectal cancer [20], patients with low TYMS expression showed better chemotherapy response and higher survival rates.

TUBB3 is the main component of microtubules, which is a structural component of the division spindle and cytoskeleton [21]. Upregulation of TUBB3 expression can destabilize microtubules and inhibit taxanes [7], which has been confirmed in various types of cancer, including breast cancer [22,23], lung cancer, ovarian cancer, prostate cancer, stomach cancer, 
and pancreatic cancer [24]. We have shown that a high level of TUBB3 expression is a favorable predictive marker in patients treated with taxotere in mono-regimen $(p=0.01)$.

Patients with low TOP $2 \alpha$ expression treated with anthracycline-containing regimens showed no response to treatment, and low survival rates $[8,25]$. This is consistent with our results. Positive expression of TOP $2 \alpha$ is associated with low rates of overall and disease-free survival ( $p=0.024$ and $p=0.039$, respectively) [26]. It is important to note that the predictive and prognostic significance of changes in the TOP $2 \alpha$ copy number remains unclear. It has been shown that the change in the number of TOP $2 \alpha$ copies is a rare genetic event (the frequency of amplifications and deletions is $9.8 \%$ and $2.7 \%$, respectively) and does not have prognostic value [27].

The expression of GSTP1 is higher in the group of chemoresistant breast tumor cells, which may be reflected in the therapeutic response of patients to treatment [4]. Thus, it was found that patients with low or absent GSTP1 expression more often had an objective response to NAC with docetaxel $(p=0.005)$ and paclitaxel $(p=0.006)$ [28]. In addition, various genetic variants of GSTP1 may play an important role in the effectiveness of platinum-based chemotherapy [5,29], as shown in our work: an initially high level of expression of this gene is associated with a low efficacy of chemotherapy according to the CP scheme $(p=0.05)$. However, interestingly, GSTP1 overexpression after NAC is associated with $100 \%$ MFS (log-rank test $p=0.02$ ). Other authors found that the presence of another disorder in the GSTP1 gene (in particular, methylation) in tumor tissue closely correlates with the clinical and pathological features of breast cancer, which indicates the possibility of using this gene for tumor diagnosis and prognosis [30].

In a recent work, it was shown that the expression levels of ERCC1, TYMS, and TOP $2 \alpha$ were significantly associated with clinical and pathological parameters: menopausal status, tumor size, lymph node metastasis, hormone receptor status, triple-negative status, $\mathrm{Ki}$ 67 index, and epidermal growth factor receptor [31]. With respect to ERCC1 gene, the higher intensity was significantly related to $\mathrm{T}_{1}$ tumor (mean rank: $64.79>42.26, p<0.001$ ), ER-positive (mean rank: $54.98>37.41, p=0.002$ ), PR-positive (mean rank: $58.35>39.05$, $p<0.001$ ) and Ki-67 < 20\% (mean rank: $66.00>44.30, p=0.001)$. In terms of TYMS gene, patients with $\mathrm{Ki}-67 \geq 20 \%$ exhibited higher expression level (mean rank: $52.76>35.40$, $p=0.011$ ). The expression TOP $2 \alpha$ intensity was higher in the premenopausal group (mean rank: $54.28>42.90, p=0.040$ ) and lymph node metastasis group (mean rank: $55.19>43.64$, $p=0.037$ ). Similar results were observed in Ki-67 $\geq 20 \%$ group (mean rank: $53.63>32.26$, $p=0.001$ ). Our analysis of the relationship of expression showed that the postoperative level of TOP1 gene is higher in patients with a large primary tumor node $(1.34 \pm 0.57)$ than in patients in the $\mathrm{T}_{1-2}$ group $(0.85 \pm 0.28)$, with $p=0.02$. The result of the analysis of the expression of TOP $2 \alpha$ is consistent with the results of this study: in patients with preserved menstrual function, there is greater expression of topoisomerase $2 \alpha(8.84 \pm 2.23)$ than in postmenopausal patients $(4.16 \pm 1.44), p=0.05$. For other genes, we did not establish a statistically significant relationship between expression and clinical and pathological parameters of patients with breast cancer.

As a result of the ROC-analysis, it was shown that the genetic results of expression showed no predictive power, except for the expression of the GSTP1 gene (AUC $=0.677$, $p=0.01$ ), which is consistent with the results of the analysis by the Kaplan-Meier method and the log-rank test. In summary, the results of the analysis in the presented study indicate that the expression of the studied genes has controversial predictive potential. However, further large-scale prospective studies with multivariate predictive analysis, in addition to control samples and the validation of a standardized method, are needed to elucidate the usefulness of these biomarkers in breast cancer.

Supplementary Materials: The following supporting information can be downloaded at: https: / / www.mdpi.com/article/10.3390/diagnostics12020405/s1, Table S1: Relationship between the expression of genes of chemosensitivity with the main clinical and pathological parameters (median/percentile 25-75\%); Table S2: The frequency of chromosomal aberrations in the genes of chemosensitivity, depending on the effect and scheme of NAC. 
Author Contributions: M.M.T. Conceptualization, Writing-Original Draft; M.K.I. Validation; E.Y.G. Resources; I.A.T. Investigation; K.A.G. Formal analysis; D.S.D. Investigation; E.A.Z. Data Curation; A.A.F. Data Curation; E.M.S. Resources, Writing—Review and Editing; N.V.L. Writing-Review and Editing. All authors have read and agreed to the published version of the manuscript.

Funding: This work was supported by the Russian Science Foundation grant No. 22-25-00499 "Changing the genetic landscape of breast tumors during neoadjuvant treatment with different chemotherapy regimens".

Institutional Review Board Statement: All procedures performed in studies involving human participants were in accordance with the ethical standards of the institutional and/or national research committee and with the 1964 Helsinki declaration and its later amendments or comparable ethical standards. The study was conducted with a permission by the local ethics committee of the Cancer Research Institute Tomsk NRMC (Protocol 1 from 14 January 2013).

Informed Consent Statement: All patients signed an informed consent.

Data Availability Statement: Database registration certificate RU 2015621620 30/10/2015 Tsyganov, M.M., Ibragimova, M.K., Deryusheva, I.V., Kazantseva, P.V., Slonimskaya, E.M., Litvyakov, N.V. Database of normal genetic variability of breast tumors and the level of expression of chemoresistance genes.

Conflicts of Interest: The authors declare no conflict of interest.

\section{References}

1. Duffy, M.J.; Crown, J. A personalized approach to cancer treatment: How biomarkers can help. Clin. Chem. 2008, 54, 1770-1779. [CrossRef]

2. Li, J.; Sun, P.; Chuang, T.; He, S.; Li, L.; Xue, G. Individualized chemotherapy guided by the expression of ERCC1, RRM1, TUBB3, TYMS and TOP2A genes versus classic chemotherapy in the treatment of breast cancer: A comparative effectiveness study. Oncol. Lett. 2020, 21, 1. [CrossRef]

3. Abdel-Fatah, T.; Ali, R.; Sadiq, M.; Moseley, P.M.; Mesquita, K.A.; Ball, G.; Green, A.R.; Rakha, E.A.; Chan, S.Y.; Madhusudan, S. ERCC1 Is a Predictor of Anthracycline Resistance and Taxane Sensitivity in Early Stage or Locally Advanced Breast Cancers. Cancers 2019, 11, 1149. [CrossRef]

4. Yang, S.J.; Wang, D.D.; Li, J.; Xu, H.Z.; Shen, H.Y.; Chen, X.; Zhou, S.Y.; Zhong, S.L.; Zhao, J.H.; Tang, J.H. Predictive role of GSTP1-containing exosomes in chemotherapy-resistant breast cancer. Gene 2017, 623, 5-14. [CrossRef]

5. Zhang, J.; Wu, Y.; Hu, X.; Wang, B.; Wang, L.; Zhang, S.; Cao, J.; Wang, Z. GSTT1, GSTP1, and GSTM1 genetic variants are associated with survival in previously untreated metastatic breast cancer. Oncotarget 2017, 8, 105905. [CrossRef]

6. Dorman, S.N.; Baranova, K.; Knoll, J.H.; Urquhart, B.L.; Mariani, G.; Carcangiu, M.L.; Rogan, P.K. Genomic signatures for paclitaxel and gemcitabine resistance in breast cancer derived by machine learning. Mol. Oncol. 2016, 10, 85-100. [CrossRef]

7. Narvi, E.; Jaakkola, K.; Winsel, S.; Oetken-Lindholm, C.; Halonen, P.; Kallio, L.; Kallio, M. Altered TUBB3 expression contributes to the epothilone response of mitotic cells. Br. J. Cancer 2013, 108, 82-90. [CrossRef]

8. O'Malley, F.; Chia, S.; Tu, D.; Shepherd, L.; Levine, M.; Huntsman, D.; Bramwell, V.; Andrulis, I.; Pritchard, K. Topoisomerase II alpha protein and responsiveness of breast cancer to adjuvant chemotherapy with CEF compared to CMF in the NCIC CTG randomized MA. 5 adjuvant trial. Breast Cancer Res. Treat. 2011, 128, 401. [CrossRef]

9. Zhong, W.; Yang, Y.; Zhang, A.; Lin, W.; Liang, G.; Ling, Y.; Zhong, J.; Yong, J.; Liu, Z.; Tian, Z. Prognostic and predictive value of the combination of TOP2A and HER2 in node-negative tumors $2 \mathrm{~cm}$ or smaller (T1N0) breast cancer. Breast Cancer 2020, 27, 1147-1157. [CrossRef]

10. Horlings, H.M.; Lai, C.; Nuyten, D.S.; Halfwerk, H.; Kristel, P.; van Beers, E.; Joosse, S.A.; Klijn, C.; Nederlof, P.M.; Reinders, M.J. Integration of DNA copy number alterations and prognostic gene expression signatures in breast cancer patients. Clin. Cancer Res. 2010, 16, 651-663. [CrossRef]

11. Nami, B.; Wang, Z. Genetics and expression profile of the tubulin gene superfamily in breast cancer subtypes and its relation to taxane resistance. Cancers 2018, 10, 274. [CrossRef]

12. Schwartz, G.F.; Hortobagyi, G.N. Proceedings of the Consensus Conference on Neoadjuvant Chemotherapy in Carcinoma of the Breast, April 26-28, 2003, Philadelphia, Pennsylvania. Breast J. 2004, 10, 273-294. [CrossRef]

13. Pfaffl, M.W. A new mathematical model for relative quantification in real-time RT-PCR. Nucleic Acids Res. 2001, 29, e45. [CrossRef]

14. Zhou, F.; Yu, Z.; Jiang, T.; Lv, H.; Yao, R.; Liang, J. Genetic polymorphisms of GSTP1 and XRCC1: Prediction of clinical outcome of platinum-based chemotherapy in advanced non-small cell lung cancer (NSCLC) patients. Age 2011, 60, 75. [CrossRef] [PubMed]

15. Herrick, J.; Sclavi, B. Ribonucleotide reductase and the regulation of DNA replication: An old story and an ancient heritage. Mol. Microbiol. 2007, 63, 22-34. [CrossRef]

16. Bepler, G.; Williams, C.; Schell, M.J.; Chen, W.; Zheng, Z.; Simon, G.; Gadgeel, S.; Zhao, X.; Schreiber, F.; Brahmer, J. Randomized International Phase III Trial of ERCC1 and RRM1 Expression-Based Chemotherapy Versus Gemcitabine/Carboplatin in Advanced Non-Small-Cell Lung Cancer. J. Clin. Oncol. 2013, 31, 2404-2412. [CrossRef] 
17. Jørgensen, C.L.; Ejlertsen, B.; Bjerre, K.D.; Balslev, E.; Nielsen, D.L.; Nielsen, K.V. Gene aberrations of RRM1 and RRM2B and outcome of advanced breast cancer after treatment with docetaxel with or without gemcitabine. BMC Cancer 2013, $13,541$. [CrossRef] [PubMed]

18. Kakimoto, M.; Uetake, H.; Osanai, T.; Shirota, Y.; Takagi, Y.; Takeshita, E.; Toriya, Y.; Danenberg, K.; Danenberg, P.V.; Sugihara, K. Thymidylate synthase and dihydropyrimidine dehydrogenase gene expression in breast cancer predicts 5-FU sensitivity by a histocultural drug sensitivity test. Cancer Lett. 2005, 223, 103-111. [CrossRef]

19. Zhang, Q.; Sun, T.; Kang, P.; Qian, K.; Deng, B.; Zhou, J.; Wang, R.; Jiang, B.; Li, K.; Liu, F. Combined analysis of rearrangement of ALK, ROS1, somatic mutation of EGFR, KRAS, BRAF, PIK3CA, and mRNA expression of ERCC1, TYMS, RRM1, TUBB3, EGFR in patients with non-small cell lung cancer and their clinical significance. Cancer Chemother. Pharmacol. 2016, 77, 583-593. [CrossRef]

20. Soong, R.; Shah, N.; Salto-Tellez, M.; Tai, B.; Soo, R.; Han, H.; Ng, S.; Tan, W.; Zeps, N.; Joseph, D. Prognostic significance of thymidylate synthase, dihydropyrimidine dehydrogenase and thymidine phosphorylase protein expression in colorectal cancer patients treated with or without 5-fluorouracil-based chemotherapy. Ann. Oncol. 2008, 19, 915-919. [CrossRef]

21. Katsetos, C.D.; Herman, M.M.; Mörk, S.J. Class III $\beta$-tubulin in human development and cancer. Cell Motil. Cytoskelet. 2003, 55, 77-96. [CrossRef] [PubMed]

22. Chen, X.; Wu, J.; Lu, H.; Huang, O.; Shen, K. Measuring $\beta$-tubulin III, Bcl-2, and ERCC1 improves pathological complete remission predictive accuracy in breast cancer. Cancer Sci. 2012, 103, 262-268. [CrossRef] [PubMed]

23. Wang, Y.; Sparano, J.A.; Fineberg, S.; Stead, L.; Sunkara, J.; Horwitz, S.B.; McDaid, H.M. High expression of class III $\beta$-tubulin predicts good response to neoadjuvant taxane and doxorubicin/cyclophosphamide-based chemotherapy in estrogen receptornegative breast cancer. Clin. Breast Cancer 2013, 13, 103-108. [CrossRef] [PubMed]

24. Sève, P.; Dumontet, C. Is class III $\beta$-tubulin a predictive factor in patients receiving tubulin-binding agents? Lancet Oncol. 2008, 9 , 168-175. [CrossRef]

25. Moretti, E.; Desmedt, C.; Biagioni, C.; Regan, M.M.; Oakman, C.; Larsimont, D.; Galardi, F.; Piccart-Gebhart, M.; Sotiriou, C.; Rimm, D.L. TOP2A protein by quantitative immunofluorescence as a predictor of response to epirubicin in the neoadjuvant treatment of breast cancer. Future Oncol. 2013, 9, 1477-1487. [CrossRef]

26. Zhao, J.; Zhang, H.; Lei, T.; Liu, J.; Zhang, S.; Wu, N.; Sun, B.; Wang, M. Drug resistance gene expression and chemotherapy sensitivity detection in Chinese women with different molecular subtypes of breast cancer. Cancer Biol. Med. 2020, $17,1014$. [CrossRef] [PubMed]

27. Chen, J.-R.; Chien, H.-P.; Chen, K.-S.; Hwang, C.-C.; Chen, H.-Y.; Yeh, K.-Y.; Hsieh, T.-Y.; Chang, L.-C.; Hsu, Y.-C.; Lu, R.-J. Amplification of HER2 and TOP2A and deletion of TOP2A genes in a series of Taiwanese breast cancer. Medicine 2017, 96 , e5582. [CrossRef]

28. Arai, T.; Miyoshi, Y.; Kim, S.; Akazawa, K.; Maruyama, N.; Taguchi, T.; Tamaki, Y.; Noguchi, S. Association of GSTP1 expression with resistance to docetaxel and paclitaxel in human breast cancers. Eur. J. Surg. Oncol. 2008, 34, 734-738. [CrossRef]

29. Schnekenburger, M.; Karius, T.; Diederich, M. Regulation of epigenetic traits of the glutathione S-transferase P1 gene: From detoxification toward cancer prevention and diagnosis. Front. Pharmacol. 2014, 5, 170. [CrossRef] [PubMed]

30. Song, B.; Wang, L.; Zhang, Y.; Li, N.; Dai, H.; Xu, H.; Cai, H.; Yan, J. Combined detection of HER2, Ki67, and GSTP1 genes on the diagnosis and prognosis of breast cancer. Cancer Biother. Radiopharm. 2019, 34, 85-90. [CrossRef]

31. Li, J.; Sun, P.; Huang, T.; He, S.; Li, L.; Xue, G. Extensive analysis of the molecular biomarkers excision repair cross complementing 1 , ribonucleotide reductase M1, $\beta$-tubulin III, thymidylate synthetase, and topoisomerase II $\alpha$ in breast cancer: Association with clinicopathological characteristics. Medicine 2021, 100, e25344. [CrossRef] [PubMed] 